Research Paper:

\title{
Predicting Mindfulness Based on Emotional Regulation and Anxiety Among High School Students in Rasht City, Iran
}

\author{
Bahman Akbari $^{{ }^{*}}$, Maryam Biabani Asli ${ }^{1}$, Jamileh Tavakoli Azad ${ }^{1}$, Shiva Aghazadeh ${ }^{1}$
}

1. Department of Psychology, Rasht Branch, Islamic Azad University, Rasht, Iran.

\begin{tabular}{|c|c|}
\hline $\begin{array}{l}\text { Use your device to scan } \\
\text { and read the article online }\end{array}$ & \\
\hline 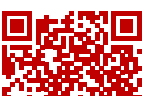 & $\begin{array}{l}\text { iety Among High School Students in Rasht. Avicenna J of Neuropsychophysiology. 2019; 6(2):75-82. http://dx.doi.org/10.32598/ } \\
\text { ajnpp.4.3.300 }\end{array}$ \\
\hline 口isyras: & d tel"http://dx.doi.org/10.32598/ajnpp.4.3.300 \\
\hline
\end{tabular}

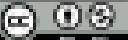

Article info:

Received: 23 Nov 2018

Accepted: 27 Feb 2019

Available Online: 01 May 2019
Keywords:

Mindfulness, Emotional regulation, Anxiety, Students

\section{ABSTRACT}

Background: Regarding the high prevalence of anxiety among students and its negative impact on their academic achievement, evaluating the efficacy of psychiatric-educational therapeutic interventions on anxiety is necessary.

Objectives: The aim of the present research was to predict mindfulness based on emotional regulation and anxiety among high school students in Rasht City, Iran.

Materials and Methods: The statistical population of the present descriptive-correlational study included all female high school students in Rasht during the academic year 2016-2017. A total of 150 individuals were selected as the sample of the study, using the random multistage cluster sampling method. In order to collect data, the mindful attention awareness scale, cognitive emotion regulation questionnaire, and children's manifest anxiety scale were used. The data were analyzed by SPSS V. 22, using the Pearson correlation coefficient and multiple regression analysis.

Results: There was a positive relationship between positive emotion regulation components and negative relationship with mindfulness $(P<0.01)$. Also, there was a negative relationship between anxiety and mindfulness $(P<0.01)$. The components of positive refocusing $(B=0.83)$, perceptiveness $(B=0.57)$, and refocus on planning $(B=0.43)$ positively predicted mindfulness. The components of catastrophizing $(B=-0.45)$, self-blame $(B=-0.37)$, rumination $(B=-0.24)$, and other-blame $(B=-0.18)$ negatively predicted mindfulness.

Conclusion: This study showed an increase in the components of acceptance, positive refocus, refocus on planning, reappraisal, and perceptiveness. Also, the rate of mindfulness increased. With an increase in catastrophizing, other-blame, self-blame, rumination, and mindfulness increased. Moreover, with an increase in anxiety, mindfulness decreased. The components of positive refocusing, perceptiveness, and refocus on planning, respectively, had the highest predictive power of mindfulness in a positive way, and the components of catastrophizing, self-blame, rumination, and other-blame, respectively, had the highest predictive power of mindfulness in a negative manner.

\section{* Corresponding Author:}

Bahman Akbari, PhD.

Address: Department of Psychology, Rasht Branch, Islamic Azad University, Rasht, Iran.

Tel: +98 (911) 1361102

E-mail: akbari@iaurasht.ac.ir 


\section{Introduction}

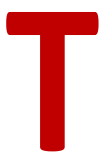

oday, in spite of creating profound cultural changes in ways of life, many people in the face of life problems lack basic and essential capabilities, thereby making them susceptible to the problems and difficulties of everyday life and its requirements [1]. One of these groups, which are exposed to social damages, is the students' group.

The high level of behavioral and emotional problems among students in different countries shows the fact that students face serious challenges in the realm of mental health. Therefore, it is necessary to pay special attention to the mental health of this group because their mental health guarantees the health of the present and future of the country [2]. One of the psychological constructs, whose influence on the quality of life has been confirmed in several studies, is the construct of mindfulness [3].

Mindfulness has long been used to reduce or eliminate life problems and psychological discomforts and distresses such as stress, anxiety, depression, behavioral problems, interpersonal conflicts, and reluctance. Mindfulness means being present at the moment with whatever that exists now without judging and without commenting about what is happening, that is, the experience of pure reality without explanation.

Mindful individuals understand the internal and external realities liberally and without distortion and have a great deal of ability in dealing with a wide range of thoughts, emotions, and experiences [4]. The foundation of mindfulness has been taken from Buddhist meditation exercises, which increases the capacity of a continuous and intelligent consciousness that goes beyond thought. Mindfulness is not a method or technique, although many different methods and techniques have been used in doing it. Mindfulness can be described as a way of understanding, which requires the perception of personal feelings [5].

Mindfulness drives away stress and worries from an individual and is not easily affected by environmental factors and conditions, and the individual expresses himself/herself through using his/her talents and innovations and deals with disapproving conditions. Therefore, an individual, who has this feature, considers himself/ herself a lovely and valuable person and does not lose time in doing his/her works. Therefore, mindfulness has a significant positive relationship with mental health [6].
The notion that mental states can have an impact on human body actions dates back to the past. Many centuries ago, thinkers had referred to the influence of mind on the body, and they had searched the cause of each disease in individuals' thoughts and lifestyles. They believed that our attitude and lifestyle could increase or stop our physiological functions [7]. Therefore, mindfulness can be considered an intermediary factor for increasing the psychological function and reducing the symptoms of stress and anxiety, which results from meditation exercises [8].

Being empowered by mindfulness, emotional regulation techniques, and ways to cope with anxiety increase the ability of individuals to compromise with a variety of stressful and challenging situations, as well as more effective management of such situations, and also increases self-esteem and life satisfaction [9].

When an individual faces a situation, good feeling and positivity are not enough to control his emotions; he needs to have the best cognitive function at these moments [10]. New theories in the realm of emotion emphasize the positive and adaptive role of sensation [11]. According to these theories, emotion can have a constructive role in problem-solving, information processing, and decision-making processes [12]. However, one should not forget that emotions are not always beneficial, and most of the time they should be regulated and managed.

Various studies have shown that individuals' capability in cognitive-emotional regulation can play an important role in their adaptation to stressful events of life [13]. Garnefski, Kraaij, and Spinhoven showed a clear relationship between the experience of negative events, emotional regulation strategies, and emotional problems. The results of their research showed that the use of some cognitive emotion regulation strategies affects each person's experience of negative life events [14]. The researchers indicated that emotional regulation while influencing the emotional and even behavioral and cognitive components of individuals' reactions to stressful situations allows them to control their intensity and duration of the emotional experiences and to regulate their emotional reactions consciously in order to reach their goals [15]. Also, regarding the emphasis of emotion regulation techniques on awareness, control, and correction of negative emotions resulting from interpersonal relationships, the use of these techniques can reduce the rumination of thought and create a positive emotion [16]. Tortella-Feliu, Balle, and Sesé [17] investigated the role of negative emotionality and 
emotion regulation in the diagnosis of depression and anxiety in adolescents aged 12-17 years. The results of this study showed that negative emotionality and negative emotion regulation strategies, such as repression and avoidance, are the major predictors for diagnosing depression and anxiety in adolescents.

Puberty and distinctive crises in this period, feeling of confusion, and the reduction of self-esteem have made this stage of life more prominent in terms of mental health [18]. Anxiety disorders also reduce the quality of life. Anxiety is one of the most common psychiatric disorders and an unpleasant feeling that is associated with an uncertain and obscure risk. Anxiety has physical symptoms (such as palpitations, heartbeat, nausea, diarrhea, and dry mouth), cognitive factors (loss of focus, being vigilant, confusion, and fear of insanity), perceptual factors (depersonalization and derealization), and behavioral factors (irritability and immobility) [19]. Anxiety is a major deterrent to students' academic achievement, which imposes significant costs on societies. Anxiety is an unpleasant experience of nervousness and emotionality in situations that an individual feels he/she is being evaluated [20].

The prevalence of various anxiety disorders differs according to different studies. In a study conducted in the United States, the prevalence of anxiety was $7.7 \%$ [21]. Regarding the disturbing effects of intellectual disturbances initiated by the complexities of present life on mental health, identifying psychological techniques and strategies that can provide and ensure the mental health of humans is a necessity. Also, considering the effective role of factors such as the ability to manage and regulate emotions, having a non-judgmental view to events, and being present in the present time on the quality of life of humans, as well as the special attention to the quality of life and performance of students as the country's future builders, the importance of the present study is apparent. This study aimed to predict mindfulness based on emotional regulation and anxiety among high school students in Rasht City, Iran.

\section{Materials and Methods}

The statistical population of the present descriptivecorrelational study consisted of all female high school students in Rasht during the academic year 2016-2017. A multistage random cluster sampling method was used. At first, 2 districts were randomly selected from the educational districts of Rasht. Then, 4 districts from each district were chosen. Finally, the students were randomly selected.
Considering the population of 463 students, the reliability coefficient was $1.96, \mathrm{P}=0.05$, the sampling accuracy was 0.05 , and the sample size was 150 . The inclusion criteria included an age range of 13-18 years and the lack of disorder or any other physical illnesses during the research.

The exclusion criteria also included the age range of over 18 years, the history of a physical illness, and the provision of incomplete information. The participants individually completed the questionnaires. As the ethical considerations of the present study, all individuals received oral information about this research and, if desired, they could participate in the research. The participants were assured that the information would be confidential and would be used only for research purposes. Moreover, in order to take into account their privacy, their names and surnames were not recorded.

\section{Mindful Awareness Attention Scale}

This questionnaire was developed by Brown and Ryan in 2003. It has 15 items that assess the individual's ability to perform an activity without paying attention to the current occurrence. Items are about being aware of emotional states, experiences and activities, overlooking peripheral issues, doing unfocused activities, doing activities without being aware of them, being unaware of the starting, and finishing time of daily activities. These questions are scored on a 6-point Likert scale.

\section{Cognitive Emotion Regulation Questionnaire}

This questionnaire was developed by Garnowski et al. in 2001. It has 36 questions, 9 subscales, and a total score. Cognitive emotion regulation questionnaire, which is composed of self-blame, acceptance, focus on thoughts/rumination, positive refocusing, refocus on planning, reappraisal, perspective development, catastrophizing, and formation, has a strong empirical and theoretical foundation. High scores in each subscale indicate the more usage of the mentioned strategy in confronting and dealing with stressful and negative events. The Persian version of the cognitive emotion regulation questionnaire in Iranian culture was standardized by Hassani [23]. The internal reliability of subscales in the Persian-speaking society was reported with an alpha coefficient from 0.76-0.92. The researchers also calculated its reliability in order to eliminate concerns about the presence of some minor cultural and age differences in the research population. Cronbach's alpha coefficient for the total scale reliability was $90 \%$ [24]. The validity 
and reliability of this questionnaire in this study were 0.79 and 0.85 , respectively.

\section{Revised Children's Manifest Anxiety Scale}

The Revised Children's Manifest Anxiety Scale was designed by Reynolds and Richmond in 1987 to assess the rate and quality of anxiety in children and adolescents. This questionnaire is suitable for individuals aged 6-19 years. It can be used by teachers, researchers, and clinicians on individuals. The validity of the children's manifest anxiety scale was assessed through test-retest and split-half with the reliability coefficients of 0.67 and 0.66 , respectively [25]. The validity and reliability of this questionnaire were 0.77 and 0.83 , respectively.

Descriptive and inferential statistics were used to analyze the data. The descriptive statistics were used to calculate frequencies and determine the central indices, dispersion, and drawing tables. In inferential statistics, the Pearson correlation coefficient (Table 1) and multiple regression were used to study the impact of the predictive variables on the criterion variable. Also, all of the statistical calculations were performed, using SPSS v. 22.

\section{Results}

The Mean \pm SD age of the students was $15.6 \pm 1.46$ (1318 years); 40 (26.7\%) student were studying in the field of humanities, $80(53.3 \%)$ in the field of experimental sciences, and $30(20 \%)$ in the field of mathematics and physics. With an increase in Mean $\pm S D$, the acceptance score was $12.2(3.2)(P<0.01)$, positive refocusing (10.4) $(P<0.01)$, refocus on planning $(P<0.01)$, positive reappraisal (9.8) $(\mathrm{P}<0.01)$, and perceptiveness 9.8 (1.4) $(P<0.01)$, the Mean $\pm S D$ of the mindfulness score increases (51.1) (16.1). With an increase in the Mean $\pm S D$ of catastrophizing, $9.6(2.7)(P<0.01)$, other-blame 11.6 (3.2) $(P<0.01)$, self-blame $12.8(3.6)(P<0.01)$, rumination (14.4) $(P<0.01)$, mindfulness decreases $(P<0.01)$. Also, with an increase in the Mean \pm SD of anxiety 13.9 (3.5), mindfulness decreases $(P<0.01)$.

The results of simultaneous regression, presented in Table 2, show that emotional regulation and anxiety explained $39 \%$ of students' mindfulness variance (criterion variable).

As presented in Table 3, the obtained value was significant $(P<0.01)$. Therefore, with a confidence of 0.99 , the prediction of students' mindfulness based on emotion regulation and anxiety was significant and the predicting variables (emotional regulation and anxiety) had the predictive power of students' mindfulness.

The components of positive focusing $(B=0.83)$, perceptiveness $(B=0.57)$, and refocus on planning $(B=0.43)$ positively predicted mindfulness. The components of catastrophizing $(B=-0.45)$, self-blame $(B=-0.37)$, rumination $(B=-0.24)$, and other-blame $(B=-0.18)$ negatively predicted mindfulness (Table 4).

Table 1. Descriptive indices of research variables and correlation coefficient of research variables with mindfulness

\begin{tabular}{|c|c|c|c|c|}
\hline \multicolumn{2}{|c|}{ Variables } & Mean $\pm S D$ & Correlation Coefficient & Sig. \\
\hline \multicolumn{2}{|c|}{ Mindfulness } & $51.2 \pm 16.1$ & - & - \\
\hline \multicolumn{2}{|c|}{ Anxiety } & $13.9 \pm 5.3$ & -0.38 & 0.01 \\
\hline \multirow{5}{*}{ Positive emotion regulation } & Acceptance & $12.2 \pm 3.6$ & 0.24 & 0.01 \\
\hline & Positive refocusing & $10.4 \pm 3.9$ & 0.46 & 0.01 \\
\hline & Refocus on planning & $10.8 \pm 3.3$ & 0.35 & 0.01 \\
\hline & Positive reappraisal & $9.9 \pm 2.8$ & 0.16 & 0.01 \\
\hline & Perceptiveness & $9.8 \pm 1.4$ & 0.28 & 0.01 \\
\hline \multirow{4}{*}{ Negative emotion regulation } & Catastrophizing & $9.6 \pm 2.7$ & -0.36 & 0.01 \\
\hline & Other-blame & $11.6 \pm 3.6$ & -0.29 & 0.01 \\
\hline & Self-blame & $12.8 \pm 3.6$ & -0.34 & 0.01 \\
\hline & Rumination & $14.3 \pm 4.5$ & -0.57 & 0.01 \\
\hline
\end{tabular}


Table 2. Summary of regression analysis to predict students' mindfulness based on emotional regulation and anxiety

\begin{tabular}{ccccc} 
Multiple Correlations & Square of Multiple Correlation $\mathbf{R}^{2}$ & Modified R $^{2}$ & Standard Error & Sig. \\
\hline Multiple Correlations of R & 0.621 & 0.386 & 7.71 & 51.84 \\
\hline
\end{tabular}

AJNPP

Table 3. Analysis of variance test for the prediction of students' mindfulness based on emotional regulation and anxiety

\begin{tabular}{ccccc}
\hline Sources of Changes & Sum of Squares & df & Mean of Squares & Sig. \\
\hline Regression & 30772.28 & 10 & 3077.23 \\
Remaining & 8251.73 & 139 & 59.37 & 0.001 \\
Total & 39024 & 124 & \\
\hline
\end{tabular}

AJNPP

Table 4. Summary of the results of the regression of predicting students' mindfulness based on emotional regulation and anxiety

\begin{tabular}{|c|c|c|c|c|c|}
\hline \multirow{2}{*}{ Variables } & \multicolumn{2}{|c|}{ Non-Standard Coefficients } & \multirow{2}{*}{$\begin{array}{c}\text { Standard Coefficients } \\
\text { B }\end{array}$} & \multirow{2}{*}{$\mathbf{T}$} & \multirow{2}{*}{ Sig. } \\
\hline & B & S.B & & & \\
\hline Fixed value & 130.06 & 10.95 & & -11.19 & 0.01 \\
\hline Anxiety & -0.426 & 0.17 & -0.141 & -2.58 & 0.03 \\
\hline Acceptance & 0.463 & 0.30 & 0.105 & 1.55 & 0.12 \\
\hline Positive refocusing & 3.40 & 0.55 & 0.839 & 6.21 & 0.01 \\
\hline Refocus on planning & -2.11 & 0.63 & 0.437 & 3.35 & 0.01 \\
\hline Positive reappraisal & 0.32 & 0.28 & 0.056 & 1.13 & 0.25 \\
\hline Perceptiveness & 6.61 & 0.59 & 0.577 & 11.15 & 0.01 \\
\hline Self-blame & -1.65 & 0.41 & -0.372 & -4.04 & 0.01 \\
\hline Rumination & -0.887 & 0.25 & -0.248 & -3.53 & 0.01 \\
\hline Catastrophizing & -2.70 & 0.33 & -0.452 & -8.19 & 0.01 \\
\hline Other-blame & 0.795 & 0.38 & -0.181 & 2.07 & 0.01 \\
\hline
\end{tabular}

\section{Discussion}

The result showed a positive relationship between positive emotion regulation components and a negative relationship with mindfulness. Also, there was a negative relationship between anxiety and mindfulness. The components of positive refocusing, perceptiveness, and refocus on planning positively predicted mindfulness. The components of catastrophizing, self-blame, rumination, and other-blame negatively predicted mindfulness.
Generally, with an increase in the components of positive emotion regulation, including acceptance, positive refocusing, refocusing on planning, positive reappraisal, and perceptiveness, the value of mindfulness increased. But, among the components of positive emotion regulation, 3 components of positive refocus, perceptiveness, and refocusing on planning could predict mindfulness; however, the components of acceptance and positive reappraisal did not predict mindfulness. This finding is inconsistent with the study of Hill and Updegraff [5], showing that the indices of emotional differentiation 
and emotional lability were composed of negative and positive emotions.

Mindfulness was associated with greater emotional differentiation and less emotional difficulties (ie emotional lability and self-reported emotion dysregulation). Emotional cognitive regulation skills can improve individuals' mindfulness through increasing positive mood. Positive emotional cognitive regulation strategies can improve individuals' mindfulness by increasing acceptance, positive refocusing, refocusing on planning, reappraisal, perceptiveness, attention, alertness, and the acceptance of emotions that affect the individual. Therefore, the predictive role of positive emotional cognitive regulation strategies seems quite logical [26].

They rely on attention and consciousness, as well as affections and emotions when positive refocusing and refocusing on planning improve mindfulness in individuals; but, in the case of the lack of prediction of mindfulness by the components of acceptance and positive reappraisal, the state of non-judgment of experiences itself is a form of reorganization that leads to the development of a general tendency to reappraise initial negative cognitions that is obtained through acceptance and reappraisal. However, it seems that high school students in the realm of perceptiveness and reappraisal have not reached enough growth and maturity and, accordingly, acceptance and positive reappraisal cannot predict mindfulness [27].

As another finding of the study, with an increase in the components of negative emotion regulation, including catastrophizing, other-blame, self-blame and rumination, the rate of mindfulness decreases and the components of catastrophizing, other-blame, self-blame, and rumination negatively predict mindfulness. In explaining the relationship between the negative emotion regulation and the mindfulness, it is worth noting that regarding the reverse relationship between the components of catastrophizing, other-blame, self-blame, and rumination with mindfulness, catastrophizing, for example, causes one to have a catastrophizing thoughts about different events, and it causes the individual to focus on different negative thoughts and reduce the mindfulness. The components of other-blame, self-blame, and rumination also cause a person to blame himself or others and ruminate about various areas of life, thereby reducing the individual's mindfulness.

Anxiety was negatively related to mindfulness. In fact, anxiety negatively predicts mindfulness. This finding is inconsistent with the research of LePera [28], which showed that mindfulness negatively correlated with anxiety, depression, and substance use. Anxiety is correlated with the concern for future events and outcomes and generates more future-related thoughts in the individual, which contradicts the mindfulness that seeks attention in the present time. Since this feeling often results from the difference between the current and the desired situation, anxiety is the stimulation of the individual's thoughts toward planning and action, which forces the person to be in a functional position. These features of anxiety have a clear contradiction with mindfulness, whose obvious characteristic is awareness at the moment. Therefore, mindfulness is associated with a better description and diagnosis of the body feeling little anxiety and disorder.

The generalization of the findings of this research is associated with some limitations. Using only written and self-measuring tools to examine the variables, as well as the completion of these measurements through observation and objective measurement help to increase the validity of these measurements. In addition, in order to generalize the results of this study better, it would be better to analyze this research in other samples. In order to define the relationships between variables more precisely in the subsequent studies, it is suitable to investigate the relationships of variables by gender. The method of this research was a correlational one and, as a result, it is not possible to rely entirely on the casual inference of its findings. But, other theoretical studies and models prove reverse findings. Therefore, in order to achieve a more precise explanation regarding the complexity of the relationships between these variables, it is necessary for other researchers to address the different dimensions of anxiety, emotion regulation, and mindfulness as the possible influencing variables.

With an increase in the components of acceptance, positive refocusing, refocus on planning, reappraisal, and perceptiveness, the rate of mindfulness increased, and with an increase in the components of catastrophizing, other-blame, self-blame, and rumination, the rate of mindfulness decreased. Also, with an increase in anxiety, the rate of mindfulness decreased. The components of positive refocusing, perceptiveness, and refocus on planning had the highest predictive power of mindfulness in a positive manner and the components of catastrophizing, self-blame, rumination, and otherblame, respectively, had the highest predictive power of the mind in a negative way. 


\section{Ethical Considerations}

\section{Compliance with ethical guidelines}

All ethical principles were considered in this article. The participants were informed about the purpose of the research and its implementation stages and signed the informed consent. They were also assured about the confidentiality of their information; moreover, they were allowed to leave the study whenever they wish and, if desired, the results of the research would be available to them, and it was approved by the Council of Graduate Studies of Islamic Azad University of Rasht (Code: 11720705961005).

\section{Funding}

This research did not receive any specific grant from funding agencies in the public, commercial, or not-forprofit sectors.

\section{Authors' contributions}

All authors contributed equally in preparing all parts of the research.

\section{Conflict of interest}

The authors declared no conflict of interest.

\section{References}

[1] Bieling PJ, Hawley LL, Bloch RT, Corcoran KM, Levitan RD, Young LT, MacQueen GM, Segal ZV. Treatment-specific changes in decentering following mindfulness-based cognitive therapy versus antidepressant medication or placebo for prevention of depressive relapse. Journal of Consulting and Clinical Psychology. 2012; 80(3):365-75. [DOI:10.1037/a0027483] [PMID] [PMCID]

[2] Padilla-Walker LM, Carlo G, Nielson MG. Does helping keep teens protected? Longitudinal bidirectional relations between prosocial behavior and problem behavior. Child Development. 2015; 86(6):1759-72. [DOI:10.1111/cdev.12411] [PMID]

[3] Bluth K, Eisenlohr-Moul TA. Response to a mindful self-compassion intervention in teens: A within-person association of mindfulness, self-compassion, and emotional well-being outcomes. Journal of Adolescence. 2017; 57(2):108-18. [DOI:10.1016/j.adolescence.2017.04.001] [PMID] [PMCID]

[4] Bruggink A, Huisman S, Vuijk R, Kraaij V, Garnefski N. Cognitive emotion regulation, anxiety and depression in adults with autism spectrum disorder. Research in Autism Spectrum Disorders. 2016; 22(1):34-44. [DOI:10.1016/j.rasd.2015.11.003]
[5] Hill CL, Updegraff JA. Mindfulness and its relationship to emotional regulation. Emotion. 2012; 12(1):81-94. [DOI:10.1037/a0026355] [PMID]

[6] Garnefski N, Kraaij V. Specificity of relations between adolescents' cognitive emotion regulation strategies and symptoms of depression and anxiety. Cognition and Emotion. 2018; 32(7):1401-8. [DOI: 10.1080/02699931.2016.1232698] [PMID]

[7] Baer RA, Lykins EL, Peters JR. Mindfulness and self-compassion as predictors of psychological wellbeing in long-term meditators and matched nonmeditators. The Journal of Positive Psychology. 2012 7(3):230-8. [DOI:10.1080/17439760.2012.674548]

[8] Omidvari S, Azin A, Montazeri A, Sadighi J, Jahangiri K, Aeenparast A. Treait anxiety among Iranians: A nationwide study. Payesh. 2011 10(3):373-80.

[9] van der Velden AM, Kuyken W, Wattar U, Crane C, Pallesen KJ, Dahlgaard J, et al. A systematic review of mechanisms of change in mindfulness-based cognitive therapy in the treatment of recurrent major depressive disorder. Clinical Psychology Review. 2015; 37(2):26-39. [DOI:10.1016/j.cpr.2015.02.001] [PMID]

[10] Kang Y, Rahrig H, Eichel K, Niles HF, Rocha T, Lepp NE, et al. Gender differences in response to a school-based mindfulness training intervention for early adolescents. Journal of School Psychology. 2018; 68(1):163-76. [DOI:10.1016/j.jsp.2018.03.004] [PMID] [PMCID]

[11] Dimidjian S, Segal ZV. Prospects for a clinical science of mindfulness-based intervention. American Psychologist. 2015; 70(7):593601. [DOI:10.1037/a0039589] [PMID] [PMCID]

[12] Burg JM, Michalak J. The healthy quality of mindful breathing: Associations with rumination and depression. Cognitive Therapy and Research. 2011; 35(2):179-85. [DOI:10.1007/s10608-010-9343-x]

[13] Dennis TA, Hajcak G. The late positive potential: A neurophysiological marker for emotion regulation in children. Journal of Child Psychology and Psychiatry. 2009; 50(11):1373-83. [DOI:10.1111/ j.1469-7610.2009.02168.x] [PMID] [PMCID]

[14] Séguin DG, MacDonald B. The role of emotion regulation and temperament in the prediction of the quality of social relationships in early childhood. Early Child Development and Care. 2018; 188(8):1147-63. [DOI:10.1080/03004430.2016.1251678]

[15] Feldman G, Greeson J, Senville J. Differential effects of mindful breathing, progressive muscle relaxation, and loving-kindness meditation on decentering and negative reactions to repetitive thoughts. Behaviour Research and Therapy. 2010; 48(10):1002-11. [DOI:10.1016/j.brat.2010.06.006] [PMID] [PMCID]

[16] Moran EK, Culbreth AJ, Barch DM. Emotion regulation predicts everyday emotion experience and social function in Schizophrenia. Clinical Psychological Science. 2018; 6(2):271-9. [DOI:10.1177/2167702617738827] [PMID] [PMCID]

[17] Tortella-Feliu M, Balle M, Sesé A. Relationships between negative affectivity, emotion regulation, anxiety, and depressive symptoms in adolescents as examined through structural equation modeling. Journal of Anxiety Disorders. 2010; 24(7):686-93. [DOI:10.1016/j. janxdis.2010.04.012] [PMID]

[18] Park JH, Han DH, Kim BN, Cheong JH, Lee YS. Correlations among social anxiety, self-esteem, impulsivity, and game genre in patients with problematic online game playing. Psychiatry Investigation. 2016 13(3):297-309. [DOI:10.4306/pi.2016.13.3.297] [PMID] [PMCID]

[19] Piet J, Hougaard E. The effect of mindfulness-based cognitive therapy for prevention of relapse in recurrent major depressive 
disorder: A systematic review and meta-analysis. Clinical Psychology Review. 2011; 31(6):1032-40. [DOI:10.1016/j.cpr.2011.05.002] [PMID]

[20] Garland EL, Gaylord SA, Fredrickson BL. Positive reappraisal mediates the stress-reductive effects of mindfulness: An upward spiral process. Mindfulness. 2011; 2(1):59-67. [DOI:10.1007/s12671-011-0043-8]

[21] Pennant ME, Loucas CE, Whittington C, Creswell C, Fonagy P, Fuggle $\mathrm{P}$, et al. Computerised therapies for anxiety and depression in children and young people: A systematic review and meta-analysis. Behaviour Research and Therapy. 2015; 67(3):1-8. [DOI:10.1016/j. brat.2015.01.009] [PMID]

[22] Chiesa A, Serretti A. Mindfulness based cognitive therapy for psychiatric disorders: A systematic review and meta-analysis. Psychiatry Research. 2011; 187(3):441-53. [DOI:10.1016/j.psychres.2010.08.011] [PMID]

[23] Hasani J. [The psychometric properties of the Cognitive Emotion Regulation Questionnaire (CERQ) (Persian)]. Journal of Clinical Psychology. 2010; 2(3):73-84.

[24] Khoury B, Lecomte T, Fortin G, Masse M, Therien P, Bouchard V et al. Mindfulness-based therapy: A comprehensive meta-analysis. Clinical Psychology Review. 2013; 33(6):763-71. [DOI:10.1016/j. cpr.2013.05.005] [PMID]

[25] Williams JM, Crane C, Barnhofer T, Brennan K, Duggan DS, Fennell MJ, et al. Mindfulness-based cognitive therapy for preventing relapse in recurrent depression: A randomized dismantling trial. Journal of Consulting and Clinical Psychology. 2014; 82(2):275-84 [DOI:10.1037/a0035036] [PMID] [PMCID]

[26] Hill CL, Updegraff JA. Mindfulness and its relationship to emotional regulation. Emotion. 2012 Feb;12(1):81. [DOI:10.1037/ a0026355] [PMID]

[27] Hülsheger UR, Alberts HJ, Feinholdt A, Lang JW. Benefits of mindfulness at work: The role of mindfulness in emotion regulation, emotional exhaustion, and job satisfaction. Journal of Applied Psychology. 2013; 98(2):310-25. [DOI:10.1037/a0031313] [PMID]

[28] Teper R, Segal ZV, Inzlicht M. Inside the mindful mind: How mindfulness enhances emotion regulation through improvements in executive control. Current Directions in Psychological Science. 2013; 22(6):449-54. [DOI:10.1177/0963721413495869]

[29] LePera N. Relationships between boredom proneness, mindfulness, anxiety, depression, and substance use. The New School Psychology Bulletin. 2011; 8(2):15-25. [DOI:10.1037/e741452011-003] [PMID] [PMCID] 